INDIAN JOURNAL OF POWER \& RIVER VALLEY DEVELOPMENT www.ijprvd.info

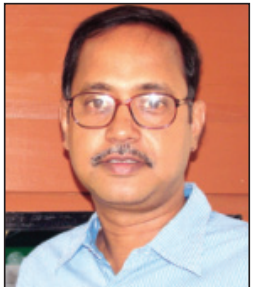

\title{
Solar-aided coal-fired hybrid power: a model under consideration
}

Solar-aided coal-fired power generation is a promising technique to reduce cost and enhance the efficiency of concentrated solar power. Operation optimization is important but has difficulty improving the performance of solar-aided coal-fired power plants, due to the fluctuations in power load and solar energy. Solar-aided coal-fired power plants (SCPPs) are attractive for the countries whose coal power dominates the power sector. Many studies have been conducted on the analyses and design optimizations of SCPP. Solar energy can be concentrated by trough solar energy collectors and tower solar collectors; then, the collected solar thermal energy is used in coal-fired power plants (CPPs). The performance of SCPP is influenced by power station capacities and solar field sizes. Steam extraction positions and power plant types also influence the energy and economic benefits of SCPP. Energy, exergy, environmental, and economic analyses on SCPP show approximately $14 \%-19 \%$ coal can be saved in the "fuel conservation mode", but the SCPP is only slightly cost effective on the basis of the cost of saved fuel.The SCPP is composed of a CPP and a trough collector system (TCS) as the solar branch. The figure shows the integration of TCS into CPP. The heaters of regenerative system work in parallel with TCS to preheat boiler feedwater. Part of the water is extracted from the inlet of a regenerative heater, preheated by the solar branch, and sent back to the water outlet of the heater either the same or in a higher place of the heater serial.
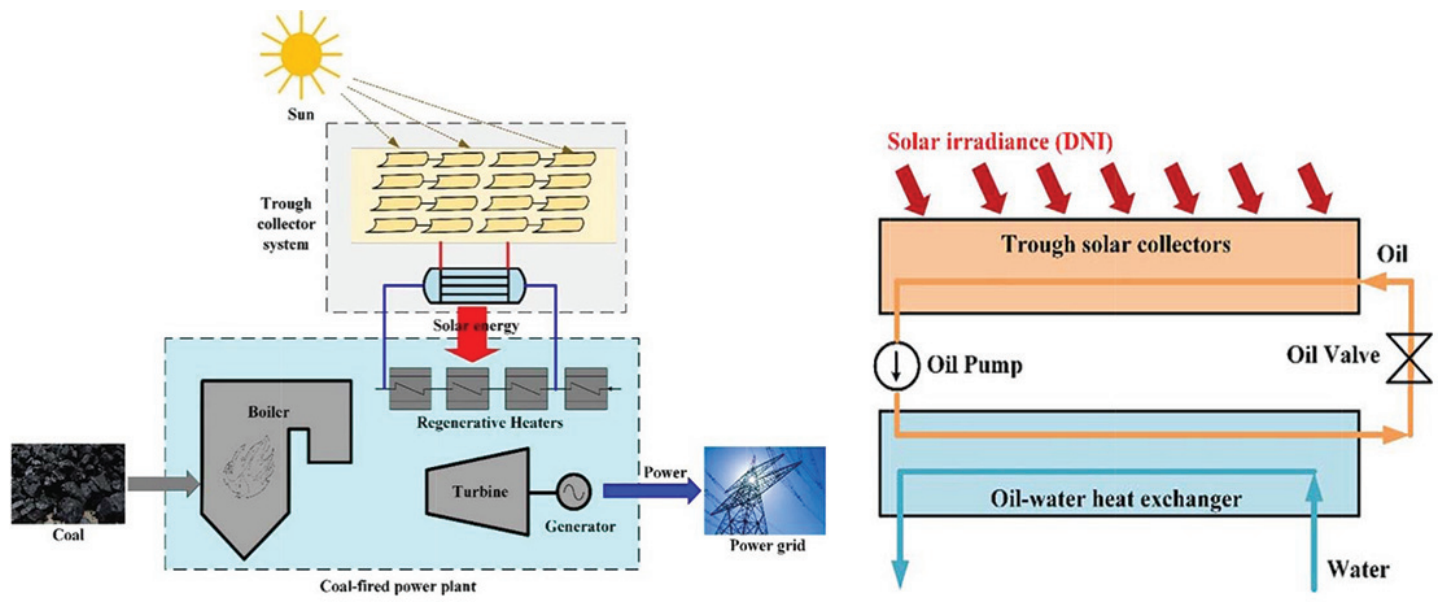

Reference and Figure Courtesy: Hui YanXinand LiJunjie Yan,” Performance analysis of a solar-aided coal-fired power plant in off-design working conditions and dynamic process “,(Journal of ) Energy Conversion and Management 20 June, 2020. 